strategy that both increases the depth of analysis and demands the large expenditure of effort in speaking and writing that is the sine qua non for developing fluency and skill. Most surprisingly, I found that responding to student's needs rather than following a tightly structured curriculum forced me to present a richly varied set of concepts while enabling me to cover more ground in one semester than I would have thought possible.

The field of informal logic has been characterized by two focuses of concern: classroom techniques and theortical analysis. These two approaches to the analysis of critical thinking appear to be another pair of dichotomies requiring incompatible processes and demanding opposing goals. My attempt to resolve the various substantive and competing demands on the structuring of Logical Thinking led to the realization that it was by simultaneously resolving both theoretical and pedagogical issues that $I$ could see my way to the resolution of, apparently, competing requirements. Any analysis of the basic concepts of informal logic requires a clear conception of the process through which thought is expressed. And so the theory of teaching critical thinking is, necessarily, bound to the analysis of the needs of students as readers, speakers and writers. Similarly, any understanding of the process through which cognitive skills are developed requires a theoretic grasp of the conceptual structures that underlie the competent performance of relevant tasks. Informal Logic is the locus of many and diverse concerns. It, more than most other areas in Philosophy, requires a commitment to that most hoary of all of the philosophical verities: practice without theory is blind; theory without practice is empty.

\section{Notes}

1. Paul, Richard, "Teaching Critical Thinking in the "Strong" Sense," in Informal Logic Newsletter, vol. iv, no. 2, May 1982, pp.2-7. I have freely adopted (and adapted) Paul's terminology. I gratefully acknowledge his priority in the indentification and the labeling of this crucial concept. 2. Kahane, Howard, Logic and Contemporary Rhetoric, Belmont CA: Wadsworth Pub. Co., 1980, 3 rd edition. 3. The paper assignment comes at, roughly, the tenth week of a fifteen week semester. For the remainder of the course I follow a different procedure. See my paper, "A Role for Formal Logic in Informal Logic Courses," in Informal Logic Newsletter, vol iv, no. 2 May 1982, pp.1315, for details.

4. My students' tendency to revert to a "fact" structure makes me suspicious of the apparent ease with which Paul's students come to the awareness of the deep levels of analysis and criticism that he describes. There are a number of theories, most of them derived from neoMarxist analysis, that offer ready made analytic structures, especially relevant to social and cultural criticism. I consider the inculcation of such pre-fabricated analytic models the opposite of critical thinking in any sense; and I hope that Paul's analysis of the "profoundly 'nationalistic' bias" of his students (pp. 5-6) does not represent the facile left-wing stereotype that was once fashionable as an alternative to careful analysis.

5. See my, "A Role for Formal Logic...,"loc.cit.

Mark Weinstein, Department of Philosophy, Hunter College, CUNY, 695 Park Avenue, New York, N.Y. 10021

\section{Teaching Informal Logic as an Emancipatory Activity}

\author{
William Maker \\ Clemson University
}

Informal logic is a relatively new subject in the philosophy curriculum, one which has emerged along with other "practical" philosophy courses such as business ethics in recent years. I think it is probably safe to say that few of us have had any formal training in it. As undergraduates we may have had a course in traditional non-symbolic logic, most likely with Copi's classic Introduction to Logic as the text. Perhaps we only studied symbolic logic. In any case, an informal poll of various colleagues who emerged from grad school around the same time as I did (1979) and who have been called upon to teach informal logic confirmed that my own experiences were by no means unique. Shortly after beginning to teach informal logic I discovered the following: That no course in logic I had had prepared me for teaching this sort of logic; that although I was teaching various upper-level courses this was the hardest one to teach; that it was difficult to find a suitable text and to decide on an overail perspective from which to teach the course. And although I am not a specialist in logic, I found myself at the end of the first semester longing for the good old days-in my case only one year before-of teaching symbolic logic.

Especially for those of us who are not logicians by training, teaching informal logic is a unique experience, one which we may well regard, at least initially, as a burden, as something we are required to do because students need such a course, because en rollments in it are high and because we are the junior members of the department. Beyond these practical matters, the fact that informal logic is designed to meet a practical needteaching students how to reason logically in a wide variety of contexts-also contributes to the unease some of us may feel about teaching it. In our other courses, even in introduction to philosophy, we are on home ground, dealing with a subject we are committed to and know well, a subject we love and regard as possessing a special significance and importance. But the connection between our own philosophical interests and labors and informal logic may seem tenuous at best. The situation appears comparable to that faced by our colleagues in literature who are called upon to teach composition.

There are various possible responses to this situation. One is to regard the teaching of informal logic as a necessary burden, as part of the price one pays for being 
among the fortunate few of recent graduates who are employed. Another response though, the one I have been prompted to take, consists in reflecting on the question of whether the initially negative reaction to teaching informal logic must be the only possible one. It is this line of thought I want to address by way of a general question: Is it necessarily the case that in teaching a practically oriented course in informal logic one must be cut off from the broader aims and interests one has as a philosopher? Put differently, I want to deal with the issue of the possible philosophical concerns, in a traditional sense, which can be met through teaching informal logic. So what follows is a personal reflection on the philosophical objectives and the philosophical justifications for informal logic. I wish to suggest that these need not be divorced from the practical objectives and justifications for it.

One of the ways of establishing or re-establishing the connection between the objectives of philosophy in a traditional sense and the practical objectives of informal logic consists in coming to see informal logic as one of the best ways of fulfilling the aims of philosophical education specifically as well as of fulfilling the broadly conceived aims of our educational field. The clue to these aims can be found in the traditional description of this field-the liberal arts. As I understand it, our aim here is that of intellectual liberation, of the broadening of the mind through education which is designed to effect the emancipation of thought from authoritarianism, unreflective orthodoxy and intolerance. This broad aim certainly has an intimate connection with philosophy. And thus $I$ am suggesting that we should consciously strive to do in informal logic in a more direct way what we have been more or less indirectly doing in our other philosophy courses: Working to bring students to an awareness of the ongoing. Socratic character of thought; giving them the experience of dealing critically with ideas; training them to recognize how assumptions, beliefs and prejudicesmany of which are concealed by the habitual and reflexive manner in which we use language and engage in discourseguide and shape our thinking, our attitudes, and the ways in which we relate to the world, ourselves and to other individuals. Why can these objectives be especially served in an informal logic course?

Most of our other philosophy courses require that we spend considerable amounts of time explicating concepts and material and rendering abstract issues intelligible. Frequently, the amount of material we cover and its complexity requires that we cannot directly teach our students about the techniques and principles of analysis, save by example. The difficulty of the subject matter often requires us to focus on insuring student comprehension and precludes their seriously becoming involved in the details and practice of analysis. At best, upper-level philosophy courses presuppose that students can think logically and critically, rather than providing the best opportunity to teach them how this is done.

What I am getting at then is simply that in a course on informal logic the techniques of critical philosophical reflection-the things we have spent considerable time trying to learn and perfect so that we can do philosophy rather than just study it-are what we should be trying to teach. In informal logic we should be trying to teach students not to become philosophers but to think like philosophers, and this can be done in part through giving them exercises where the basic techniques of philosophical analysis are mundanely applicable.
In suggesting that a course in informal logic can function in a direct way to be both practically useful and to fulfill the traditional aims of liberal education through focusing on the perspectives and techniques of philosophical analysis, I am also suggesting something else, which may not be as obvious as what I have already said. This is the notion that the practical dimension in informal "practical" logic has two related senses. I believe that the practical objective, in one sense, of teaching students how to think critically so that they can perform successfully in college and beyond need not be divorced from a practical objective in the older sense of the term. According to the latter, I mean practical in the sense which it concerns the values and standards for proper human action. In short, I believe that the practical concern of critical thinking-of the search for the truth-is intimately connected with the practical concern with the good life. As I see it, teaching informal logic is essentially or in the last analysis an ethical activity. I came to think in this way through searching for a justification for some of the rules and guidelines for rational thought and argument which we teach. Specifically, I began to reflect on why an appeal to fear constitutes a bad argument, and I was driven to consider our overall criteria of rationality themselves and what end or ends they ultimately serve. In concluding that teaching logic is an ethical activity, I mean this not in the sense that we teach ethics, but rather in the sense that in teaching logic we appeal to canons or criteria of rationality which have a decidedly extra-theoretical normative force.

What is the connection between the two senses of the word 'practical'? It seems to me that an implicit justification for our criteria of rationality and one aim toward which we apply them and ask our students to accept them is that they set guidelines for and further the attainment of a situation which is free of confusion, distorition, onesidedness and aperspectivism both in regard to one's understanding of one's own viewpoint as well in regard to one's understanding of the viewpoint of others. Insofar as our criteria of rationality do serve that end, we can see, I believe, a further and perhaps a final justification for them: These criteria, by making possible effective communication and understanding, are ultimately in the service of and make possible human freedom.

There are several assumptions which underlie my connection of our criteria of rationality with effective communication and thereby with freedom. First, 1 understand freedom to be the capacity for individual self-determination. Also, I am assuming that the context in which individual freedom is realized is fundamentally not monological but dialogical. Which is to say that freedom consists in an intersubjective relation between individuals in the sense that any particular individual's freedom to choose and act presupposes a context in which others possess the same capacity. Freedom is thus understood not as unrestricted action-as license-but as interaction framed by social, political and linguistic structures which render individual self-determination possible because they articulate and preserve a mutually acknowledged space for uncoerced choice. Consequently, individual freedom is seen to presuppose an interactive situation in which there is at least a minimal amount of mutual recognition and mutual respect between individual selves. Fundamentally, it presupposes a mutual recognition of the possible legitimacy of distinct and perhaps different viewpoints and perspectives. The need for shared recognition and respect suggests that both self-understanding and the understanding of others are required for freedom, 
and such understanding itself presupposes a communicative situation which is at least relatively purged of falsehood, distortion, prejudice and onesidedness. That is, a situation in which one can attain clarity about the nature and the degree of justifiability of one's own opinions, beliefs and views as well as those of others.

Especially crucial to such an ideal of effective communication is the absence of distortion. Distorted communication, leading to the failure to attain self-understanding as well as understanding of others, can have a variety of sources, causes and manifestations. Most basic to it is a stance or frame of mind identifiable as aperspectivism. Aperspectivism in its most extreme form consists in unconscious one-sidedness and blind intolerance to the possible legitimacy of the views, beliefs and opinions of others. It is rooted in an unwarranted and unchallenged faith in the self-evident correctness of one's own opinions, in ignorance concerning the notion that points of view require justification, and in a lack of awareness concerning this uncritical one-sidedness and of the factors-historical, political, cultural, linguistic and personal-which shape and reinforce it.

Such an attitude or frame of mind distorts communication because it undercuts both the need for and the possibility of understanding others, and thus ultimately of understanding oneself. Insofar as one is blindly certain of one's own position, open-ended and possibly self-corrective communication with others is unnecessary. Similarly, such dogmatic self-certainty precludes the likelihood, if not the possibility, of attempting to put oneself in another's position and of thus seeing things as someone else sees them.

Freedom of course cannot be identified with or restricted to the intellectual self-determination which effective communication makes possible. While it is not a sufficient condition for the actualization of freedom, effective communication would seem to be a necessary condition and a cornerstone for other forms of non-coerced and non-coercive action. Insofar as an individual's attitudes, beliefs and opinions can and do shape and guide their choices of action, then aperspectivism and the various factors which produce and reinforce it function to block and inhibit freedom. Aperspectivism blocks maximum uncoerced self-determination because: (1) One's own choices are in effect coerced, unfree, to the extend to which one is unaware as well as uncritical of the various notions and factors which shape them. (2) One's own possible courses of action are unduly limited because one is unaware of alternatives. (3) Insofar as on is unaware that one's particular perspective is just that, no reasons exist for recognizing the right of others to choose courses of action based on differing viewpoints. Correspondingly, one invites a similar stance on the part of others. Aperspectivism thus legitimates coercion-of others by oneseif, of oneself by others. It does so because it functions to ground and preserve a situation in which unreflected, uncritical and hence possibly unlegitimated authoritydomination-can prevail.

Thus the criteria of rationality which we teach can be understood as setting guidelines for and as making possible self-understanding through mutual understanding, and they can serve as effective standards for the interactive realization of both through communication. In this sense neither these standards nor the intersubjective communication which they make possible are ends in themselves.
Rather, the ultimate and final end aim and justification for rationality is practical in the most fundamental sense: Intellectual emancipation from aperspectivism through critical and mutually constituted communicative understanding serves finally the approximate attainment of an ideal of non-coercive free human interaction. That is, it serves the realization of individual and collective selfdetermination. The criteria of rationality do not automatically validate any particular ethical viewpoint or political stance. Rather, they serve to make possible effective communication about and the critical assessment of different concrete positions. So the emancipation I am speaking of is primarily intellectual, although it assumes that an adequate understanding of the world, of oneself and of others is a prerequisite for rational action. Such understanding presupposes and is made possible by the critical activity of coming to the awareness of the extent to which we are imbedded in linguistic and ideational perspectives which have blind spots.

How does this understanding of how informal logic relates to and serves the philosophical objectives I have outlined guide the way in which I teach the course? What techniques do I employ to stress the emancipatory character of the rules and criteria for logical and critical reasoning? Beyond covering the traditional subject matter of informal logic-fallacies, the nature and forms of arguments, argument structure, analysis, reconstruction and so on-1 generally work to indicate the basic nature and features of uncritical one-sidedness, pointing out its deficiencies and specifying those factors in language and argumentation which can and do function to support it. From the start of the course I give-and ask students to find and analyze-examples of discourse which illustrate and illuminate both distorted and undistorted communication. In this context I also assign readings where these matters are specifically considered and exposed: Orwell's "Politics and the English Language," Langer's "The Power and Peril of Language," Cassirer's "A Clue to the Nature of Man: The Symbol," and Baker's "Pricks and Chicks."

Most students have given little thought to the nature and functions of language, to the non-natural character of words as signs, and thus they fail to appreciate the extent to which meanings are conventionally established and are thus susceptible to fluctuation from person to person and culture to culture, as well as to change over time and distortion. So I spend time illustrating the flexible character of language and exposing the extent to which imbedded meanings can and do function to shape our points of view. Of special importance in this context is pointing out the verbal character of many disputes. This involves indicating how choice, individual as well as social, functions in determining the meaning of crucial terms, and it also involves specifying the factors which make adequate definitions difficult to obtain. Beyond this, my aim here is to bring students to an awareness of the considerable extent to which the words we use reveal on examination hidden and often unjustified assumptions and prejudices. I also aim to make them aware that the terms we use to depict and assess certain "facts" can vary widely, often lead to different understandings of the facts and are frequently ordained, not in a clear and direct manner by the facts themselves, but by the perspective from which we view the facts. To the se ends I assign essays focusing on current issues in which the terms of the debate are especially crucial and whose exact meanings are hard to establish or are themselves controversial: Issues centering around such terms as "justice," pornography," "human rights," 
"free economy" etc. In one such assignment I ask students to consider whether the abortion controversy is a factual or a verbal dispute, requiring not that they present their views on abortion, but that they attempt to clarify the nature of the dispute and how they think it might be resolved.

Overall, it seems to me that we, as philosophers, can make a special and distinct contribution in teaching informal logic, a contribution which is practical in both of the senses mentioned. Our skills in logical and conceptual analysis enable us to serve the immediately practical end of teaching students the basic techniques of critical thinking which they can apply to any subject matter. Our philosophical knowledge of the nature and functions of language and of the principles which philosophically ground and legitimate the rules and techniques of analysis enables us to also stress the ultimate ends which the activity of thought serve. And appreciating the extent to which informal logic can work to clarify and make students aware of the latter ends can help us to appreciate informal logic as a course in which we can fulfill our broader philosophical obligations and objectives.

What have I gained personally from teaching informal logic? Just as there are two senses of the word "practical" in my conception of the practical dimension of informal logic, there are also two senses in which I understand the ambiguous expression "teaching informal logic as emancipatory activity." One of these is the sense in which one teaches students that logically critical thought serves intellectual emancipation and the capacity for individual self-determination. The second sense is that in which the activity of teaching such a course is, or can be, emancipating as regards one's own perspective. In my case this has meant specifically that I have begun to envision an underlying compatibility between the two philsophical traditions in which I have studied: the Anglo-American tradition of analysis, with its stress on logic, language and clarity, and the continental traditions of critical theory and hermeneutics, with their stress on the relation between thought and the human condition.

Professor William Maker, Department of History, Philosophy and Religion, Clemson University, Clemson, SC 29631.

\title{
Appraising Argumentative Texts: Justificatory and Defensive Components
}

\author{
Dale Moberg \\ Hobart and William Smith Colleges
}

Section One: The Quasiformal Approach

One familiar approach to argument appraisal in critical thinking courses involves analyzing and arranging the various premises, conclusions, and inferences and then assessing the validity of the inferences (or perhaps the degree of support given the conclusion by the premises). For appraisal to rise above the intuitive level, it seems necessary to introduce the usual classification of logically complex sentences and natural deduction inference rules associated with them. This additional regimentation re quires augmenting analytic procedures; typically, one needs to supply missing intermediate conclusions and premises, and paraphrase to achieve greater uniformity of expression by condensing to eliminate irrelevant phrases or by expanding to replace pronouns, uncover tacit semantic linkages, or clarify elliptical phrases.

I think the best way to understand explicitly what is meant by the quasiformal approach is to consider a typical argumentative text (1):

(1) What are the economic prospects for the coming year? Either the tax rate structure will have to be modified to generate additional revenue or a federal deficit will occur. Reagan has made it perfectly clear that taxes won't increase. In addition, it seems reasonable to believe that economic improvement now requires a balanced budget it's apparent, then, that the economy won't improve in the short term.

Text (1) presents a straightforward exercise for quasiformal analysis, being neither excessively complex in its inferential structure. nor very enthymematic, nor containing many extraneous prefixes, phrases. and remarks. A typical quasiformal analysis and structuring for text (1) is provided by diagram (2): 